Check for updates

Cite this: RSC Adv., 2019, 9, 35904

Received 16th September 2019 Accepted 28th October 2019

DOI: $10.1039 / c 9 r a 07457 k$

rsc.li/rsc-advances

\section{Discovery of dihydrooxazolo[2,3-a]isoquinoliniums as highly specific inhibitors of hCE2 $\uparrow$}

\author{
Lixia Ding,,$^{\text {ac }}$ Lu Wang,,$^{\mathrm{b}}$ Kun Zou,,$^{\mathrm{a}}$ Bo Li, (D) *ad Yunqing Song, ${ }^{\mathrm{b}}$ Qihua Zhang, ${ }^{\mathrm{a}}$

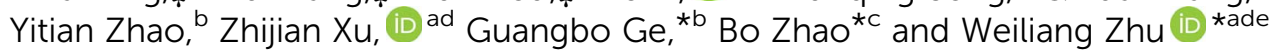

Human carboxylesterase 2 (hCE2) is one of the most abundant esterases distributed in human small intestine and colon, which participates in the hydrolysis of a variety of ester-bearing drugs and thereby affects the efficacy of these drugs. Herein, a new compound (230) with a novel skeleton of dihydrooxazolo[2,3-a]isoquinolinium has been discovered with strong inhibition on hCE2 $\left(\mathrm{IC}_{50}=1.19\right.$ $\left.\mu \mathrm{M}, K_{\mathrm{i}}=0.84 \mu \mathrm{M}\right)$ and more than 83.89 fold selectivity over hCE1 (IC $\left.50>100 \mu \mathrm{M}\right)$. Furthermore, 230 can inhibit hCE2 activity in living HepG2 cells with the $\mathrm{IC}_{50}$ value of $2.29 \mu \mathrm{M}$, indicating that this compound has remarkable cell-membrane permeability and is capable for inhibiting intracellular hCE2. The SAR (structure-activity relationship) analysis and molecular docking results demonstrate that the novel skeleton of oxazolinium is essential for hCEs inhibitory activity and the benzyloxy moiety mainly contributes to the selectivity of hCE2 over hCE1.

\section{Introduction}

Mammalian carboxylesterases (CEs), important members of the serine hydrolase superfamily widely distributed in the lumen of endoplasmic reticulum in various tissues, are responsible for the hydrolysis of a wide range of endogenous and xenobiotic substrates containing ester, amides, thioesters and carbamates. ${ }^{1-3}$ In human body, hCE1 and hCE2 are the main carboxylesterases, both of which play crucial roles in endo- and xenobiotic metabolism. As one of the most abundant esterases distributed in human small intestine and colon, hCE2 participates in hydrolysis of the ester-bearing drugs (such as irinotecan, prasugrel, capecitabine, flutamide) and thereby affects the efficacy of these drugs. ${ }^{4-7}$ For instance, CPT-11 (irinotecan), an anticancer prodrug, exhibits strong anti-colorectal cancer activity by releasing the effective substance $\mathrm{SN}-38$. However, excessive accumulation of $\mathrm{SN}-38$ in the intestinal mucosa leads

${ }^{a}$ Key Laboratory of Receptor Research, Drug Discovery and Design Center, Shanghai Institute of Materia Medica, Chinese Academy of Sciences, 555 Zuchongzhi Road, Shanghai 201203, China.E-mail: boli@simm.ac.cn; wlzhu@simm.ac.cn

${ }^{b}$ Shanghai University of Traditional Chinese Medicine, 1200 Cailun Road, Shanghai 201203, China. E-mail: geguangbo@dicp.ac.cn

${ }^{c}$ College of Chemistry and Materials Science, Nanjing Normal University, 1 Wenyuan Road, Nanjing 210097, China. E-mail: zhaobo@njnu.edu.cn

${ }^{d}$ University of Chinese Academy of Sciences, No. 19A Yuquan Road, Beijing 100049, China

${ }^{e}$ Open Studio for Druggability Research of Marine Natural Products, Pilot National Laboratory for Marine Science and Technology (Qingdao), 1 Wenhai Road, Aoshanwei, Jimo, Qingdao, 266237, China

$\dagger$ Electronic supplementary information (ESI) available. See DOI: 10.1039/c9ra07457k

\$ These authors made equal contributions to this work. to delayed-onset diarrhoea even death. ${ }^{8-10}$ To improve the potential clinical risk of these drugs, some highly specific hCE2 inhibitors have been used in clinical to reduce the local exposure of SN-38 in the intestinal mucosa, thereby ameliorating the intestinal toxicity of CPT-11. ${ }^{\mathbf{1 1 , 1 2}}$ Over the past decade, a wide variety of hCE2 inhibitors have been reported, including the natural triterpenoids, ${ }^{13,14}$ flavonoids, ${ }^{13-15}$ 1,2-diones ${ }^{16,17}$ and etc. Although many compounds with strong hCE2 inhibitory activities have already been developed, the potent and specific inhibitors targeting intracellular hCE2 are still rarely reported.

DCZ0358 (Fig. 1) is a novel dihydrooxazolo[2,3- $a$ ]isoquinolinium discovered in the synthesis of berberine analogues. ${ }^{18-20}$ Preliminary screening indicated that DCZ0358 could effectively inhibit the catalytic activity of both hCE1 ( IC $_{50}$ $=4.04 \mu \mathrm{M})$ and hCE2 $\left(\mathrm{IC}_{50}=16.03 \mu \mathrm{M}\right)$, while its hydrolyzate 23b showed a significant reduction of the inhibitory activity (hCE1 $\mathrm{IC}_{50}=36.80 \mu \mathrm{M} ;$ hCE2 $\mathrm{IC}_{50}=41.75 \mu \mathrm{M}$ ), which demonstrated that the oxazolinium moiety of DCZ0358 is essential for the $\mathrm{CE}_{\mathrm{S}}$ inhibitory activity (Fig. 1). In the synthesis of derivatives of DCZ0358, we have found that in addition to compound 23d (Fig. 2), other compounds with modification of the substituents on the A and D rings cause structural instability

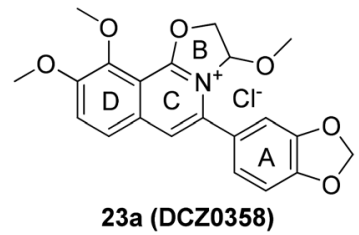<smiles>COc1ccc2cc(-c3ccc4c(c3)OCO4)n(C(CO)OC)c(=O)c2c1OC</smiles>

Fig. 1 Structures of 23a (DCZ0358) and 23b. 
<smiles></smiles>

$23 d(83 \%)$<smiles></smiles><smiles></smiles><smiles></smiles>

$23 \mathrm{~m}(86 \%)$<smiles></smiles>

$23 \mathrm{e}(86 \%)$<smiles>COc1ccc(-c2cc3ccc(OC)c(OC)c3c3[n+]2C(Cl)(COc2ccc([N+](=O)[O-])cc2)OCC3OC)cc1OC</smiles>

$23 \mathrm{~h}(86 \%)$<smiles>COc1ccc(-c2cc3ccc(OC)c(OC)c3c3[n+]2C(Cl)(OC)OCC3OC)cc1OCc1ccc(C)cc1</smiles><smiles>COc1ccc(-c2cc3ccc(OC)c(OC)c3c3[n+]2C(OC)CO3)cc1OCc1ccc(C(C)C)cc1</smiles>

$23 n(90 \%)$<smiles>COC(=O)c1ccc(COc2cc(-c3cc4ccc(OC)c(OC)c4c4[n+]3C(Cl)CO4)ccc2OC)cc1</smiles><smiles>COC1=COc2cc1c1c3c(OC)c(OC)ccc3cc(-c3ccc(OC)c(OCc4ccc(C(F)(F)F)cc4)c3)c1[n+]2Cl</smiles><smiles>COc1ccc(-c2cc3ccc(OC)c(OC)c3c3[n+]2C(OC)CO3)cc1OCc1ccc(-c2ccccc2)cc1</smiles><smiles></smiles>

$230(95 \%)$

Fig. 2 The structures of compounds $23 \mathrm{~d}-0$.

of the quaternary ammonium salt. Moreover, the bioactivity and selectivity of 23d were improved (for hCE2 $\mathrm{IC}_{50}=6.889 \mu \mathrm{M}$ with $>14.52$-fold selectivity over hCE1). These results encouraged us to make further investigation of the structure-inhibition relationships of these berberine analogues as CEs inhibitors.

The previously reported synthetic route of DCZ0358 is inconvenient to prepare more derivatives because of the harsh reaction conditions (Scheme 1). ${ }^{21}$ Therefore, we designed a new synthetic route using compound $\mathbf{1 2}$ as the key intermediate (Scheme 2). Among the obtained new analogues, 23o showed the highest selectivity and the best inhibitory activity (hCE1 IC I0 $_{50}$ $>100 \mu \mathrm{M}$; hCE2 $\left.\mathrm{IC}_{50}=1.192 \mu \mathrm{M}, K_{\mathrm{i}}=0.84 \mu \mathrm{M}\right)$. It was also found that 230 could inhibit hCE2 activity in living HepG2 cells with the $\mathrm{IC}_{50}$ value of $2.29 \mu \mathrm{M}$, suggesting that the compound has remarkable cell-membrane permeability and is capable for inhibiting intracellular hCE2. Further molecular docking results showed that the methoxyl group at the benzyloxy ring of 230 could tightly bind to the catalytic amino acid Ser-228 via $\mathrm{H}$ bonding, which may account for the high selectivity of 230 on hCE2 over hCE1.

\section{Results and discussion}

\section{Synthetic procedures}

Previously, we reported the synthetic route of DCZ0358 (Scheme 1). ${ }^{21}$ However, the application of $n$-butyl lithium reagent and low temperature condition $\left(-78{ }^{\circ} \mathrm{C}\right)$ restricted the synthesis of derivatives. Therefore, developing a feasible route is important<smiles>CCOC(=O)c1c(CCl)ccc(OC)c1OCCOC</smiles><smiles>CCOC(=O)c1c(C)ccc(OC)c1OC</smiles><smiles>COc1ccc2cc(-c3ccc4c(c3)OCO4)[n+]3c(c2c1OC)OCC3OC</smiles><smiles>C=CC(=C)c1cc2ccc(OC)c(OC)c2c(OCC(OC)OC)n1</smiles><smiles>C=C(/C=C\C)/C=C(\C)c1ccc2c(c1)OCO2</smiles><smiles>N#[N+]c1ccc2c(c1)OCO2</smiles><smiles>COc1ccc(C)c(C(=O)O)c1OC</smiles>

23a(DCZ0358)

Scheme 1 The original synthetic route. 

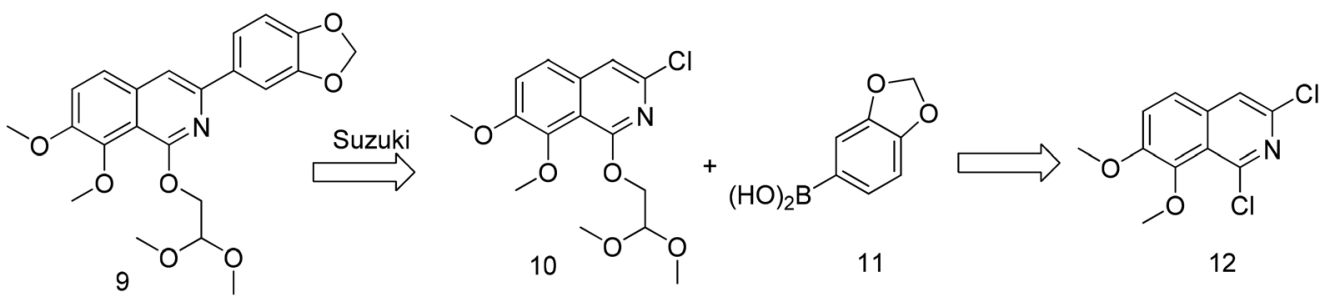

Scheme 2 The retrosynthetic analysis.

for the further medicinal chemistry research. Based on the retrosynthetic analysis (Scheme 1), compound 9 could be synthesized via Suzuki coupling reaction from 10 and $\mathbf{1 1}$. Compound 10 could be smoothly prepared from the key intermediate 12.

Firstly, 6,7-dimethoxy-1-indanone $\mathbf{1 3}$ was adopted as the starting material (Scheme 3). After oximation of 13 with tertbutyl nitrite under acidic condition, ketoxime 14 was obtained through filtration. ${ }^{22-24}$ Subsequently, compound 14 was hydrolyzed by sodium hydroxide, and then dehydrated by $p$-toluenesulfonyl chloride to give benzonitrile $15 .^{24}$ Finally, 15 was cyclized and chloridized by $\mathrm{PCl}_{5}$ to provide the dichloroisoquinoline 12. ${ }^{24}$ However, the starting material 13 is very expensive and difficult to be prepared, which promoted us searching for alternative synthetic route.

Thus, we developed another route taking commercially available 3,4-dimethoxybenzaldehyde $\mathbf{1}$ as the starting material (Scheme 4). Compound 1 reacted with DMF and formic acid to afford tertiary amine 2 in $75 \%$ yield. ${ }^{25}$ Then we added chloroformate to the mixture of 2 and $n$-butyl lithium under $-78{ }^{\circ} \mathrm{C}$ to produce 16 in $80 \%$ yield. ${ }^{26,27} \mathrm{Next}$, compound 16 was attracted by electrophilic reagent TMSCN to afford 17 (82\% yield). ${ }^{28}$ The operation for the hydrolysis of the methyl ester compound $\mathbf{1 7}$ to the compound 15 is difficult to be control. Subsequently, both ester and cyano groups were hydrolyzed to carboxyl groups under strong alkaline condition to give 18 (76\% yield). Compound 18 was easily dehydrated in the presence of acetyl chloride to obtain compound 19 in $78 \%$ yield. ${ }^{29}$ However, compound 20 was rather difficult to achieve from compound 18 or compound 19. After trying various amines, we found that only ammonium carbonate could react with $19 .{ }^{30}$ However, this reaction occurred at a high temperature $\left(280{ }^{\circ} \mathrm{C}\right)$ and gave a very low yield (22\% yield) of $\mathbf{2 0}$. Thus, compound $\mathbf{1 7}$ was directly reacted with sodium methoxide to afford compound $\mathbf{2 1}$ in 51\% yield, followed by demethylation to produce dihydroisoquinoline-1,3-dione 20 with a high yield of $93 \% .^{31}$ In order to convert 20 to the key intermediate $\mathbf{1 2}$, we explored many reagents, such as $\mathrm{PCl}_{5}, \mathrm{POCl}_{3}, \mathrm{SOCl}_{2}$ and $\mathrm{PhPOCl}_{2}$, it turned out that $\mathrm{PhPOCl}_{2}$ behaved the best yield with $47 \%{ }^{31}$

The key intermediate $\mathbf{1 2}$ reacted smoothly with hydroxyacetal under alkaline conditions to give compound $\mathbf{1 0}$ with high yield (98\%), ${ }^{32}$ and then 10 reacted with various arylboronic acids containing a benzyloxy structure to produce 22 in yields ranging from $46 \%$ to $98 \% .^{19}$ Finally 22 were cyclized under acidic conditions to give a series of dihydrooxazolo[2,3-a]isoquinolinium analogues (Scheme 5, compounds 23d-23o in Fig. 2). The present synthetic route is convenient to scale up and benefits further pharmaceutical research.

\section{Biological activity assays}

We designed and synthesized more than 30 derivatives of DCZ0358. However, the five-ring quaternary ammonium component of some derivatives was unstable to decompose easily into its hydrolyzate $23 \mathbf{b}$. With 12 stable compounds in hand, we conducted experiments to assay inhibitory activities against both hCE1 and hCE2 using a panel of fluorescent probe substrates. $^{33-36}$ D-Luciferin methyl ester (DME) was used as a probe substrate, and nevadensin (a specific hCE1 inhibitor) was used as a positive inhibitor control for hCE1. Fluorescein diacetate (FD) was used as a specific probe substrate, and loperamide (LPA) was used as a positive inhibitor control of hCE2. The $\mathrm{IC}_{50}$ values of all derivatives were evaluated and listed in Table 1.

Table 1 showed that the inhibitory effects of these compounds against hCE2 were enhanced significantly when the methylenedioxy group on A ring was changed into benzyloxy group. The $\mathrm{IC}_{50}$ values of $23 \mathrm{n}\left(\mathrm{hCE} 2 \mathrm{IC}_{50} 1.66 \pm 0.21 \mu \mathrm{M}\right)$ and $23 \mathrm{o}\left(\mathrm{hCE} 2 \mathrm{IC}_{50}\right.$ $1.19 \pm 0.10 \mu \mathrm{M}$ ) were improved more than tenfold comparing to that of $23 \mathrm{a}\left(\mathrm{hCE} 2 \mathrm{IC}_{50} 16.03 \pm 1.49 \mu \mathrm{M}\right)$. However, different types of the substituents on the A ring didn't have significant effects on the inhibitory activities, e.g., 23k (hCE2 IC $\left._{50} 5.58 \pm 0.94 \mu \mathrm{M}\right), 231$ (hCE2 IC $\left._{50} 2.64 \pm 0.45 \mu \mathrm{M}\right), 23 \mathrm{~m}\left(\right.$ hCE2 IC $\left._{50} 2.33 \pm 0.20 \mu \mathrm{M}\right), 23 n$ $\left(\mathrm{hCE} 2 \mathrm{IC}_{50} 1.66 \pm 0.21 \mu \mathrm{M}\right)$ and $230\left(\mathrm{hCE} 2 \mathrm{IC}_{50} 1.19 \pm 0.10 \mu \mathrm{M}\right)$
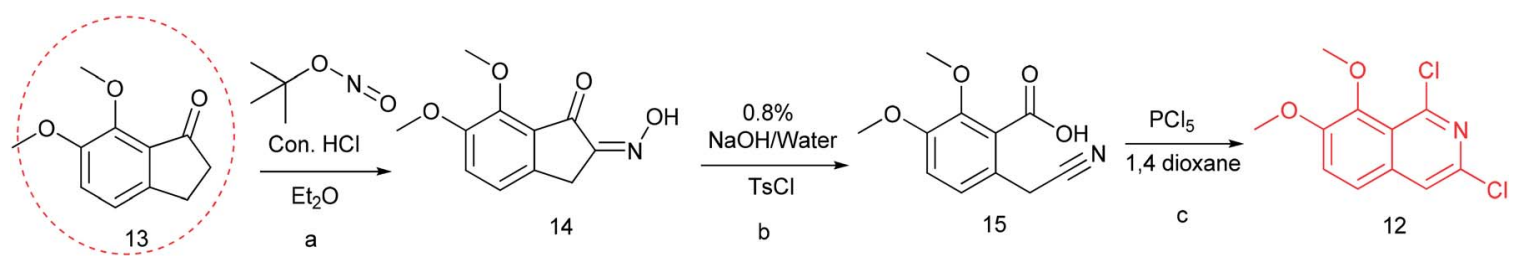

Scheme 3 The synthesis of compound 12. Reagents and conditions: (a) tert-butyl nitrite, $\mathrm{HCl}$ (cat.), diethyl ether, r.t., $2 \mathrm{~h}$; (b) $\mathrm{NaOH}(8 \%), 50{ }^{\circ} \mathrm{C}$; Tos Cl, $80{ }^{\circ} \mathrm{C}, 3 \mathrm{~h}$; (c) $\mathrm{PCl}_{5}, 1,4$-dioxane, $90^{\circ} \mathrm{C}, 12 \mathrm{~h}$. 

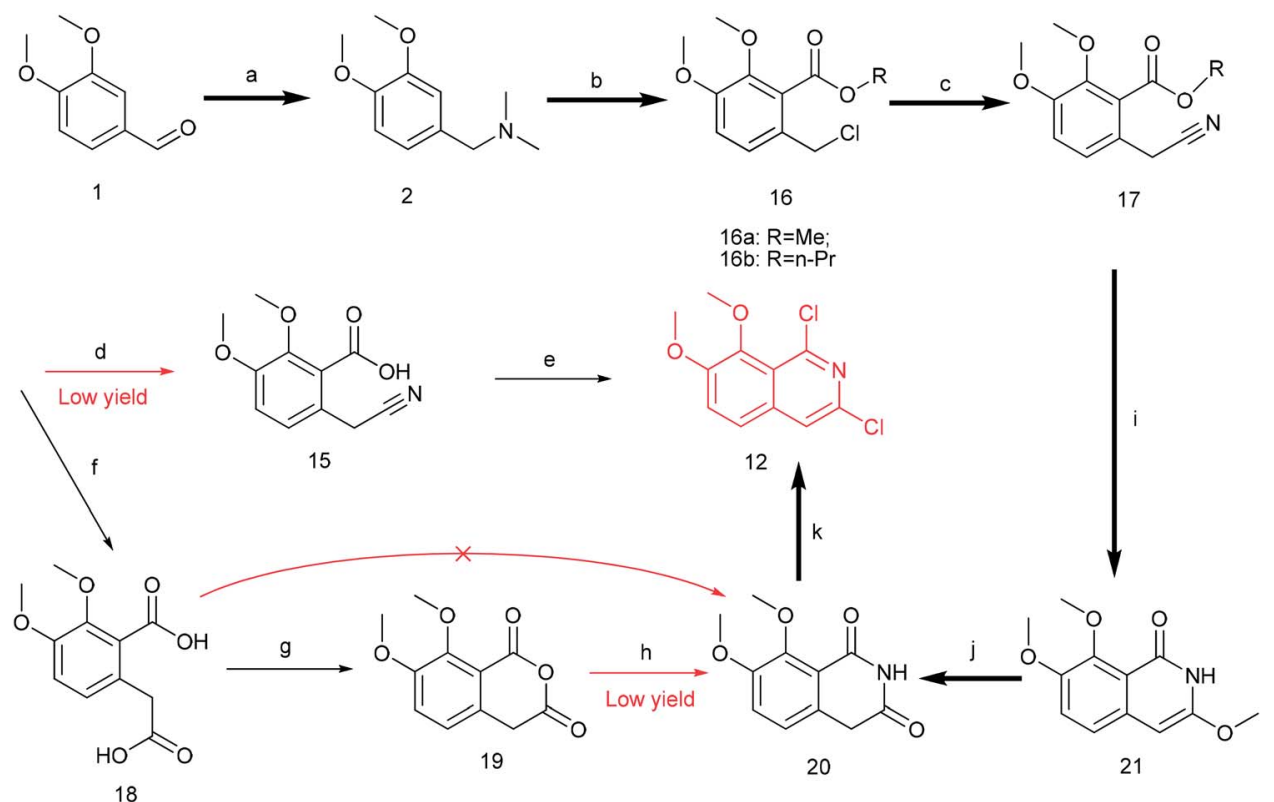

Scheme 4 The synthesis of compound 12. Reagents and conditions: (a) DMF, $\mathrm{HCOOH}, 150{ }^{\circ} \mathrm{C}, 5 \mathrm{~h} ;(\mathrm{b}) \mathrm{n}-\mathrm{BuLi}\left(0^{\circ} \mathrm{C}\right), \mathrm{ClCOOCH}_{3} / \mathrm{ClCOOC}_{3} \mathrm{H}_{7}$ $\left(-78{ }^{\circ} \mathrm{C}\right)$, dry THF, r.t $12 \mathrm{~h}$; (c) TMSCN, TBAF, MeCN, $80{ }^{\circ} \mathrm{C} 12 \mathrm{~h}$; (d) $\mathrm{NaOH}(2.9 \mathrm{M}), 1,4$-dioxane, $40{ }^{\circ} \mathrm{C}, 3 \mathrm{~h}$; (e) PCl$, 1,4-\mathrm{dioxane}, 90{ }^{\circ} \mathrm{C}, 12 \mathrm{~h}$; (f) $\mathrm{NaOH}(10 \mathrm{M}), 1,4$-dioxane, $90^{\circ} \mathrm{C}, 8 \mathrm{~h}$; (g) AcCl, $50^{\circ} \mathrm{C}, 2 \mathrm{~h}$; (h) $\left(\mathrm{NH}_{4}\right)_{2} \mathrm{CO}_{3}, 280^{\circ} \mathrm{C}, 2 \mathrm{~h}$; (i) $\mathrm{MeONa}$, dry MeOH, $80^{\circ} \mathrm{C} 1 \mathrm{~h}$; (j) $\mathrm{MeOH}, \mathrm{HCl}(3 \mathrm{M}), 100{ }^{\circ} \mathrm{C}$ $1 \mathrm{~h}$; (k) $\mathrm{PhPOCl}_{2}, 160{ }^{\circ} \mathrm{C}, 3 \mathrm{~h}$.

with electron-donating groups on the benzyloxy ring were similar to that of 23e (hCE2 IC $\left._{50} 11.46 \pm 1.76 \mu \mathrm{M}\right), 23 f\left(\right.$ hCE2 IC $_{50} 5.73 \pm$ $0.79 \mu \mathrm{M})$ and $23 \mathrm{~h}\left(\mathrm{hCE} 2 \mathrm{IC}_{50} 3.32 \pm 0.87 \mu \mathrm{M}\right)$ with electronwithdrawing groups. In terms of the selectivity, it improved apparently according to the values of $\mathrm{IC}_{50}$ (hCE2)/IC ${ }_{50}$ (hCE1) shown in Table 1 . For instance, the value of $\mathrm{IC}_{50}$ (hCE2)/ $/ \mathrm{IC}_{50}$ (hCE1) of 230 was up to 83 while that of 23a was only 0.25 . Thus, 230 have the best selectivity on hCES2 among all these newly synthesized compounds.

Collectively, the structure-activity relationships of these compounds were summarized as follows, (1) the oxazolinium moiety is crucial for the inhibitory activity against hCEs; (2) the benzyloxy group on the A ring mainly contributed to the selectivity of hCE2 over hCE1 (Fig. 3).

The inhibition kinetic of 230 against hCE2-mediated FD hydrolysis has been carefully investigated and the results showed that 230 functioned as a mixed inhibitor against hCE2mediated FD hydrolysis, with the $K_{\mathrm{i}}$ value of $0.84 \mu \mathrm{M}$ (Fig. $4 \mathrm{~B}$ ). Furthermore, in view of that hCE2 is an intracellular enzyme, the inhibition potential of $\mathbf{2 3 0}$ was also investigated. As shown in Fig. 5, 230 could strongly inhibit intracellular hCE2-mediated NCEN hydrolysis and reduce the fluorescence intensity in the green channel (for the hydrolytic metabolite of NCEN) in living HepG2 cells via a dose-dependent manner. Meanwhile, the $\mathrm{IC}_{50}$<smiles></smiles>

Scheme 5 The synthesis of DCZ0358 analogues. Reagents and conditions: (a) $\mathrm{NaH}$, glycolaldehyde dimethyl acetal, $\mathrm{THF}, \mathrm{r} . \mathrm{t} .12 \mathrm{~h}$; (b) Pd ${ }_{2}(\mathrm{dba})_{3}$, Xphos, $\mathrm{K}_{3} \mathrm{PO}_{4}, 1,4$-dioxane, $90{ }^{\circ} \mathrm{C}, 12$ h; (c) acetone, $\mathrm{HCl}-\mathrm{Et}_{2} \mathrm{O}$ (5 : 1), r.t. 1 h. 
Table 1 The $\mathrm{IC}_{50}$ values of DCZ0358 and its derivatives on hCE1 and hCE2 ${ }^{a}$

\begin{tabular}{|c|c|c|c|}
\hline Compound & $\mathrm{IC}_{50}(\mu \mathrm{M})$ for hCE1 & $\mathrm{IC}_{50}(\mu \mathrm{M})$ for hCE2 & Selectivity $\mathrm{IC}_{50}(\mathrm{hCE} 2) / \mathrm{IC}_{50}(\mathrm{hCE} 1)$ \\
\hline $23 a$ & $4.04 \pm 0.40$ & $16.03 \pm 1.49$ & $>0.25$ \\
\hline $23 \mathbf{b}$ & $36.80 \pm 7.70$ & $41.75 \pm 18.15$ & $>0.88$ \\
\hline $23 e$ & $>100$ & $11.46 \pm 1.76$ & $>8.72$ \\
\hline $23 f$ & $>100$ & $5.73 \pm 0.79$ & $>17.46$ \\
\hline $23 g$ & $>100$ & $3.33 \pm 0.32$ & $>30.07$ \\
\hline $23 \mathbf{j}$ & $>100$ & $3.77 \pm 0.25$ & $>26.51$ \\
\hline $23 k$ & $>100$ & $5.58 \pm 0.94$ & $>17.94$ \\
\hline 231 & $>100$ & $2.64 \pm 0.45$ & $>37.89$ \\
\hline $23 \mathrm{~m}$ & $>100$ & $2.33 \pm 0.20$ & $>42.81$ \\
\hline $23 n$ & $>100$ & $1.66 \pm 0.21$ & $>60.31$ \\
\hline $230^{a}$ & $>100$ & $1.19 \pm 0.10$ & $>83.89$ \\
\hline
\end{tabular}

${ }^{a}$ Inhibition potential of all compounds were investigated in living HepG2 cells. ${ }^{b}$ Nevadensin was used as a positive inhibitor of hCE1. ${ }^{c}$ LPA was used as a positive inhibitor of hCE2.

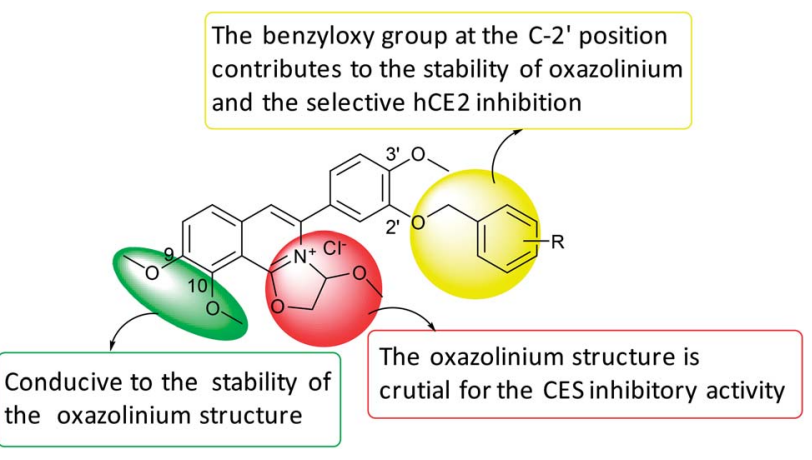

Fig. 3 SAR summary of DCZ0358 analogues.
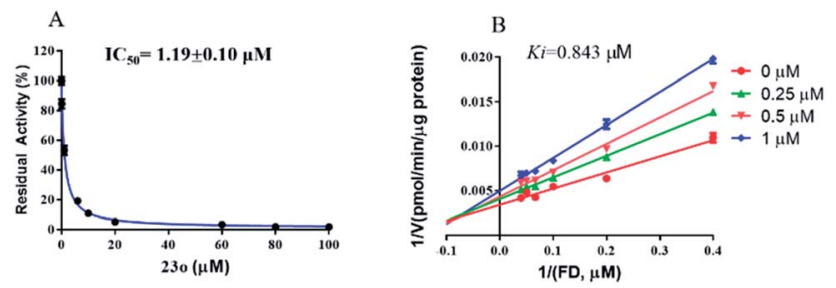

Fig. 4 The dose-dependent inhibition curve of $230(\mathrm{~A})$ and the Lineweaver-Burk plots of 230 against hCE2-mediated FD hydrolysis (B).

value of 230 against intracellular hCE2 was also evaluated as $2.29 \mu \mathrm{M}$ (Fig. S2B $\dagger$ ).

\section{Molecular docking}

In order to investigate the interaction mechanism of 230 with hCE2, molecular docking of $\mathbf{2 3 0}$ to the active site of hCE2 was performed. As shown in Fig. 6, there are hydrogen bond between the methoxyl of ring D with Arg-355 (3.16 $\AA$ ), and a Ttype $\pi-\pi$ interaction between the ring $\mathrm{D}$ with the Arg-355, as well as, hydrogen bond between the oxygen atom of ring B with
Phe-307 (3.17 $\AA$ ) in the entrance of the active cavity of hCE2. These interactions facilitate the entry of 230 into the active cavity of hCE2. However, the hydrolysate of 230 cannot enter the active cavity of hCE2, due to its small inlet. In addition, the methoxyl group at the benzyloxy end of 230 could tightly bind to the catalytic amino acid Ser-228 (1.6 ̊) via strong H-bonding, as well as, with Ala-150 (3.18 $)$ ), and there are strong hydrophobic interactions between the benzyloxy group of 230 with the key residues in the active cavity of hCE2. These interactions may account for the high selectivity of 230 on hCE2. The strong $\mathrm{H}$ bond interaction between 230 and Ser-228 indicates that 230 may obstruct hCE2-mediated hydrolysis, possibly because Ser-

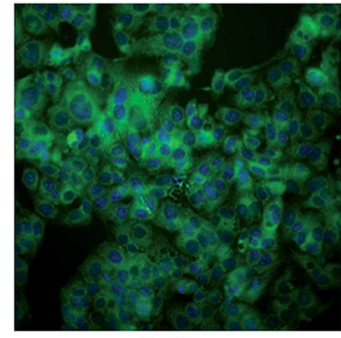

$0 \mu \mathrm{M}$

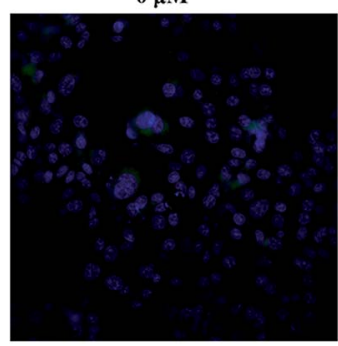

$10 \mu \mathrm{M}$

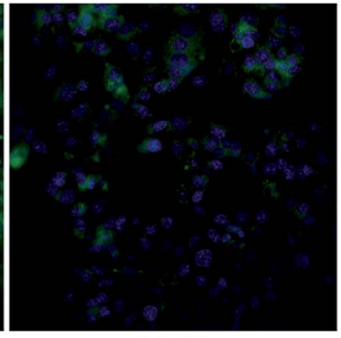

$2.5 \mu \mathrm{M}$

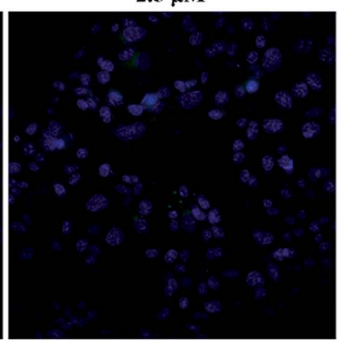

$20 \mu \mathrm{M}$
Fig. 5 The images of HepG2 cells stained with NCEN $(10 \mu \mathrm{M})$ and Hoechst $33342(1 \mu \mathrm{M})$ at $37{ }^{\circ} \mathrm{C}$ for $50 \mathrm{~min}$ in the presence of 230 at various concentrations $(0 \mu \mathrm{M}, 2.5 \mu \mathrm{M}, 10 \mu \mathrm{M}$ and $20 \mu \mathrm{M})$. All data was shown as mean $\pm \mathrm{SD}$. 


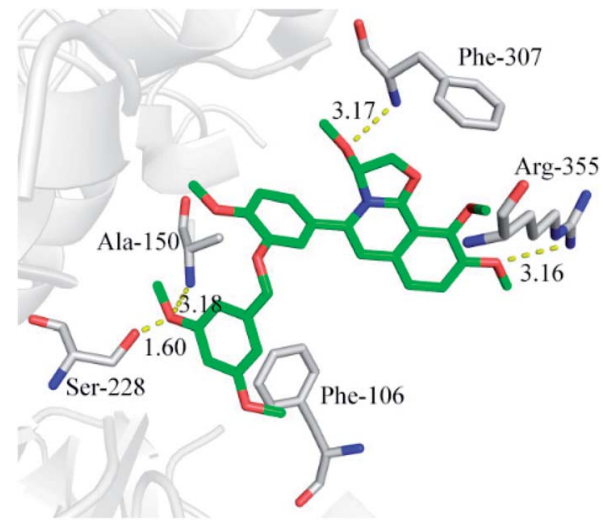

Fig. 6 Molecular docking indicates the interactions between compound 230 and hCE2.

228 is an important residue involved in substrate recognition and catalysis of hCE2. These findings agreed well with the experimental data where 230 exhibited much more potent inhibitory effect on hCE2 but a relatively weaker one on hCE1.

\section{Conclusions}

A new compound 230 with a novel skeleton of dihydrooxazolo [2,3-a] isoquinolinium was discovered with good inhibitory activity on hCE2 $\left(\mathrm{IC}_{50}=1.19 \mu \mathrm{M}, K_{\mathrm{i}}=0.84 \mu \mathrm{M}\right)$ and high selectivity over hCE1 $\left(\mathrm{IC}_{50}>100 \mu \mathrm{M}\right)$. The SAR (structureactivity relationship) analysis and molecular docking results revealed that the novel oxazolinium moiety is essential for hCE2 inhibitory activity, while the benzyloxy moiety contributes to the selectivity of hCE2 over hCE1. Furthermore, 230 could strongly inhibit intracellular hCE2 in living HepG2 cells, with the IC $_{50}$ value of $2.29 \mu \mathrm{M}$. These findings are important for further research and development of hCE2 inhibitors with high specificity and efficacy.

\section{Experimental}

\section{Chemical synthesis}

Materials. All starting materials were obtained from commercial suppliers and used without further purification. The ${ }^{1} \mathrm{H}$ and ${ }^{13} \mathrm{C}$ NMR spectra were taken on Bruker Avance-600 or 500 or 400 , Varian MERCURY Plus-400 or 300 NMR spectrometer operating at $400 \mathrm{MHz}$ or $300 \mathrm{MHz}$ for ${ }^{1} \mathrm{H}$ NMR, 125 MHz or $100 \mathrm{MHz}$ for ${ }^{13} \mathrm{C}$ NMR, using TMS as internal standard and $\mathrm{CDCl}_{3}$ or methanol- $d_{4}$ or DMSO- $d_{6}$ as solvent. ${ }^{13} \mathrm{C}$ NMR spectra were recorded with complete proton decoupling. The ESI-MS or EI-MS was recorded on Finnigan LCQ/DECA or Thermo-DFS, respectively. The HRMS were obtained from Micromass Ultra Q-TOF (ESI) or Thermo-DFS (EI) spectrometer. Flash column chromatography was carried out using silica gel (200-400 mesh). Thin layer chromatography (TLC) was used silica gel F254 fluorescent treated silica that were visualised under UV light (254 nm).

Synthetic procedure. Compounds DCZ0358 and 23b have been reported in our previous work. ${ }^{18,20}$ Synthesis of 3,9,10- trimethoxy-5-(4-methoxy-3-((4-methoxybenzyl)oxy)phenyl)-2,3dihydrooxazolo[2,3-a]isoquinolin-4-ium (23d). To a solution of $22 \mathrm{~d}(56 \mathrm{mg}, 0.1 \mathrm{mmol})$ in acetone $(5 \mathrm{~mL})$ was added hydrochloric acid ( $1 \mathrm{~mL}, 2.0 \mathrm{M}$ in diethyl ether), and then the mixture was stirred for $2 \mathrm{~h}$ at room temperature. The solution was evaporated in vacuo to obtain the titled compound 23d as yellow solid (46 mg, 83\%). ${ }^{1} \mathrm{H}$ NMR (500 MHz, DMSO- $\left.d_{6}\right) \delta 8.15(\mathrm{~s}, 1 \mathrm{H})$, $7.99(\mathrm{~s}, 1 \mathrm{H}), 7.81(\mathrm{~s}, 1 \mathrm{H}), 7.34(\mathrm{~s}, 2 \mathrm{H}), 7.13(\mathrm{~s}, 3 \mathrm{H}), 6.91(\mathrm{~s}, 2 \mathrm{H})$, $6.62(\mathrm{~s}, 1 \mathrm{H}), 5.30(\mathrm{~s}, 1 \mathrm{H}), 5.20(\mathrm{~s}, 1 \mathrm{H}), 4.69(\mathrm{~s}, 2 \mathrm{H}), 4.02(\mathrm{~s}, 3 \mathrm{H})$, $3.95(\mathrm{~s}, 3 \mathrm{H}), 3.85(\mathrm{~s}, 3 \mathrm{H}), 3.73(\mathrm{~s}, 3 \mathrm{H}), 2.95(\mathrm{~s}, 3 \mathrm{H}) .{ }^{13} \mathrm{C}$ NMR $(125$ MHz, DMSO- $\left.d_{6}\right) \delta 161.2,159.7,152.9,149.9,147.3,146.2,136.8$, $134.5,130.9,130.1,126.1,124.9,124.5,120.9,118.8,116.5$, 114.5, 112.8, 110.6, 90.9, 76.5, 62.3, 57.5, 56.3, 55.8, 55.7, 46.8. HRMS (EI) calcd for $\mathrm{C}_{30} \mathrm{H}_{17} \mathrm{O}_{7} \mathrm{~N} 503.1000[\mathrm{M}]^{+}$, found 503.0990.

3,9,10-Trimethoxy-5-(4-methoxy-3-((4-(methylsulfonyl)benzyl) oxy)phenyl)-2,3-dihydrooxazolo[2,3-a]isoquinolin-4-ium (23e). Compound 23e was prepared from compound $22 \mathrm{e}(58 \mathrm{mg}, 0.1$ mmol) as a yellow solid (48 mg, 86\%). ${ }^{1} \mathrm{H}$ NMR (400 MHz, DMSO- $\left.d_{6}\right) \delta 8.18(\mathrm{~d}, J=7.6 \mathrm{~Hz}, 1 \mathrm{H}), 7.97(\mathrm{~d}, J=7.2 \mathrm{~Hz}, 3 \mathrm{H}), 7.87$ $(\mathrm{s}, 1 \mathrm{H}), 7.73(\mathrm{~s}, 2 \mathrm{H}), 7.44(\mathrm{~s}, 1 \mathrm{H}), 7.32(\mathrm{~s}, 1 \mathrm{H}), 7.26(\mathrm{~s}, 1 \mathrm{H}), 6.62(\mathrm{~s}$, $1 \mathrm{H}), 5.33(\mathrm{~m}, 4 \mathrm{H}), 4.13-3.82(\mathrm{~m}, 9 \mathrm{H}), 3.22(\mathrm{~s}, 3 \mathrm{H}), 2.85(\mathrm{~s}, 3 \mathrm{H})$. ${ }^{13} \mathrm{C}$ NMR (125 MHz, DMSO- $\left.d_{6}\right) \delta 161.1,153.0,151.3,147.9$, $146.2,143.2,140.8,136.4,134.4,128.7,127.7,126.2,124.9$, $124.3,123.3,119.1,114.9,112.9,110.5,91.0,76.4,69.8,62.3$, 57.5, 56.4, 55.8, 44.0. HRMS (EI) calcd for $\mathrm{C}_{29} \mathrm{H}_{29} \mathrm{O}_{8} \mathrm{NS} 551.1608$ $[\mathrm{M}]^{+}$, found 551.1607 .

3,9,10-Trimethoxy-5-(4-methoxy-3-((4-(methoxycarbonyl)benzyl) oxy)phenyl)-2,3-dihydrooxazolo[2,3-a]isoquinolin-4-ium (23f). Compound 23f was prepared from compound $22 \mathrm{f}(56 \mathrm{mg}, 0.1$ mmol) as a yellow solid (50 mg, 93\%). ${ }^{1} \mathrm{H}$ NMR (600 MHz, $\left.\mathrm{CDCl}_{3}\right) \delta 8.17(\mathrm{~d}, J=8.9 \mathrm{~Hz}, 2 \mathrm{H}), 8.01(\mathrm{~s}, 2 \mathrm{H}), 7.99(\mathrm{~s}, 1 \mathrm{H}), 7.86(\mathrm{~s}$, $1 \mathrm{H}), 7.61(\mathrm{~d}, J=7.8 \mathrm{~Hz}, 2 \mathrm{H}), 7.42(\mathrm{~s}, 1 \mathrm{H}), 7.32(\mathrm{~m}, 1 \mathrm{H}), 7.25(\mathrm{~d}, J$ $=8.4 \mathrm{~Hz}, 1 \mathrm{H}), 6.61(\mathrm{~d}, J=6.0 \mathrm{~Hz}, 1 \mathrm{H}), 5.33(\mathrm{~m}, 2 \mathrm{H}), 5.27(\mathrm{~m}$, $1 \mathrm{H}), 5.22(\mathrm{~m}, 1 \mathrm{H}), 4.04(\mathrm{~s}, 3 \mathrm{H}), 3.97(\mathrm{~s}, 3 \mathrm{H}), 3.89(\mathrm{~s}, 3 \mathrm{H}), 3.85(\mathrm{~s}$, $3 \mathrm{H}), 2.86(\mathrm{~s}, 3 \mathrm{H}) .{ }^{13} \mathrm{C}$ NMR $\left(125 \mathrm{MHz}\right.$, DMSO- $\left.d_{6}\right) \delta$ 166.5, 161.1, 153.0, 151.3, 148.0, 146.2, 142.7, 136.4, 134.4, 129.8, 129.6, 128.1, 126.1, 124.9, 124.3, 123.2, 119.1, 114.9, 112.9, 110.6, 91.0, 76.4, 70.0, 62.3, 57.4, 56.4, 55.8, 52.7. HRMS (EI) calcd for $\mathrm{C}_{30} \mathrm{H}_{29} \mathrm{O}_{8} \mathrm{~N} 531.1888[\mathrm{M}]^{+}$, found 531.1882.

5-(3-((4-Cyanobenzyl)oxy)-4-methoxyphenyl)-3,9,10-trimethoxy2,3-dihydrooxazolo[2,3-a]isoquinolin-4-ium (23g). Compound $\mathbf{2 3 g}$ was prepared from compound $22 \mathrm{~g}(53 \mathrm{mg}, 0.1 \mathrm{mmol})$ as a yellow solid (46 mg, 92\%). ${ }^{1} \mathrm{H}$ NMR (600 MHz, DMSO- $\left.d_{6}\right) \delta 8.17(\mathrm{~d}, J=$ $9.0 \mathrm{~Hz}, 1 \mathrm{H}), 8.01(\mathrm{~d}, J=9.0 \mathrm{~Hz}, 1 \mathrm{H}), 7.90(\mathrm{~d}, J=4.2 \mathrm{~Hz}, 2 \mathrm{H}), 7.86$ $(\mathrm{s}, 1 \mathrm{H}), 7.66(\mathrm{~d}, J=7.8 \mathrm{~Hz}, 2 \mathrm{H}), 7.43(\mathrm{~d}, J=1.8 \mathrm{~Hz}, 1 \mathrm{H}), 7.33(\mathrm{dd}$, $J=8.4,1.8 \mathrm{~Hz}, 1 \mathrm{H}), 7.26(\mathrm{~d}, J=7.8 \mathrm{~Hz}, 1 \mathrm{H}), 6.64(\mathrm{~d}, J=6.0 \mathrm{~Hz}$, 1H), $5.34(\mathrm{~m}, 2 \mathrm{H}), 5.29(\mathrm{~m}, 1 \mathrm{H}), 5.24(\mathrm{~m}, 1 \mathrm{H}), 4.05(\mathrm{~s}, 3 \mathrm{H}), 3.98$ (s, 3H), $3.90(\mathrm{~s}, 3 \mathrm{H}), 2.87(\mathrm{~s}, 3 \mathrm{H}) \cdot{ }^{13} \mathrm{C}$ NMR $\left(125 \mathrm{MHz}\right.$, DMSO- $\left.d_{6}\right)$ $\delta$ 161.1, 153.0, 151.3, 147.8, 146.2, 143.0, 136.3, 134.4, 133.0, $128.6,126.1,124.9,124.3,123.3,119.2,119.1,114.8,112.9$, 111.1, 110.6, 91.0, 76.4, 69.7, 62.3, 57.4, 56.4, 55.8. HRMS (EI) calcd for $\mathrm{C}_{29} \mathrm{H}_{26} \mathrm{O}_{6} \mathrm{~N}_{2} 498.1785[\mathrm{M}]^{+}$, found 498.1785.

3,9,10-Trimethoxy-5-(4-methoxy-3-((4-nitrobenzyl)oxy)phenyl)2,3-dihydrooxazolo[2,3-a]isoquinolin-4-ium (23h). Compound 23h was prepared from compound $22 \mathrm{~h}(55 \mathrm{mg}, 0.1 \mathrm{mmol})$ as a yellow solid ( $45 \mathrm{mg}, 86 \%$ ). ${ }^{1} \mathrm{H}$ NMR (400 MHz, DMSO- $\left.d_{6}\right) \delta 8.30$ $(\mathrm{d}, J=8.4 \mathrm{~Hz}, 2 \mathrm{H}), 8.19(\mathrm{~d}, J=9.2 \mathrm{~Hz}, 1 \mathrm{H}), 8.01(\mathrm{~d}, J=9.2 \mathrm{~Hz}$, 
1H), $7.87(\mathrm{~s}, 1 \mathrm{H}), 7.74(\mathrm{~d}, J=8.4 \mathrm{~Hz}, 2 \mathrm{H}), 7.43(\mathrm{~s}, 1 \mathrm{H}), 7.34(\mathrm{~d}, J=$ $8.4 \mathrm{~Hz}, 1 \mathrm{H}), 7.28$ (d, $J=8.4 \mathrm{~Hz}, 1 \mathrm{H}), 6.66(\mathrm{~d}, J=5.2 \mathrm{~Hz}, 1 \mathrm{H})$, 5.44-5.35 (m, 2H), $5.34(\mathrm{~s}, 1 \mathrm{H}), 5.23(\mathrm{~d}, J=6.4 \mathrm{~Hz}, 1 \mathrm{H}), 4.05(\mathrm{~s}$, $3 \mathrm{H}), 3.98(\mathrm{~s}, 3 \mathrm{H}), 3.91(\mathrm{~s}, 3 \mathrm{H}), 2.89(\mathrm{~s}, 3 \mathrm{H}) .{ }^{13} \mathrm{C}$ NMR $(125 \mathrm{MHz}$, DMSO- $\left.d_{6}\right) \delta 160.6,152.5,150.8,147.3,147.1,145.7,144.6,135.8$, $133.9,128.3,125.7,124.4,123.8,123.6,122.9$, 118.6, 114.4, 112.4, 110.1, 90.5, 75.9, 69.1, 61.8, 56.9, 55.9, 55.3. HRMS (EI) calcd for $\mathrm{C}_{28} \mathrm{H}_{26} \mathrm{O}_{8} \mathrm{~N}_{2} 518.1684[\mathrm{M}]^{+}$, found 518.1688 .

3,9,10-Trimethoxy-5-(4-methoxy-3-((4-(trifluoromethyl)benzyl) oxy)phenyl)-2,3-dihydrooxazolo[2,3-a]isoquinolin-4-ium (23i). Compound $23 \mathbf{i}$ was prepared from compound $22 \mathbf{i}$ (57 mg, 0.1 $\mathrm{mmol})$ as a yellow solid (48 $\mathrm{mg}, 88 \%) .{ }^{1} \mathrm{H}$ NMR $(500 \mathrm{MHz}$, DMSO- $\left.d_{6}\right) \delta 8.20(\mathrm{~d}, J=7.2 \mathrm{~Hz}, 1 \mathrm{H}), 8.03(\mathrm{~d}, J=6.8 \mathrm{~Hz}, 1 \mathrm{H}), 7.89$ $(\mathrm{s}, 1 \mathrm{H}), 7.82(\mathrm{~d}, J=6.0 \mathrm{~Hz}, 2 \mathrm{H}), 7.72(\mathrm{~d}, J=6.4 \mathrm{~Hz}, 2 \mathrm{H}), 7.46(\mathrm{~s}$, $1 \mathrm{H}), 7.35(\mathrm{~d}, J=6.4 \mathrm{~Hz}, 1 \mathrm{H}), 7.28(\mathrm{~d}, J=6.4 \mathrm{~Hz}, 1 \mathrm{H}), 6.64(\mathrm{~s}, 1 \mathrm{H})$, $5.36(\mathrm{~m}, 3 \mathrm{H}), 5.27$ (s, 1H), 4.07 (s, 3H), $4.01(\mathrm{~s}, 3 \mathrm{H}), 3.93(\mathrm{~s}, 3 \mathrm{H})$, $2.88(\mathrm{~s}, 3 \mathrm{H}) .{ }^{13} \mathrm{C}$ NMR $\left(125 \mathrm{MHz}, \mathrm{DMSO}-d_{6}\right) \delta 160.6,152.5,150.8$, $147.4,145.7,141.6,135.9,133.9,128.1,125.7,125.4,125.4$, 124.4, 123.8, 122.7, 119.4, 118.6, 114.3, 112.4, 110.1, 90.5, 75.9, 69.3, 61.8, 56.9, 55.9, 55.3. HRMS (EI) calcd for $\mathrm{C}_{29} \mathrm{H}_{26} \mathrm{O}_{6} \mathrm{NF}_{3}$ $541.1707[\mathrm{M}]^{+}$, found 541.1710 .

3,9,10-Trimethoxy-5-(4-methoxy-3-(quinolin-7-ylmethoxy) phenyl)-2,3-dihydrooxazolo[2,3-a]isoquinolin-4-ium

Compound $23 \mathbf{j}$ was prepared from compound $22 \mathbf{j}$ ( $58 \mathrm{mg}, 0.1$ $\mathrm{mmol})$ as a yellow solid (45 mg, 85\%). ${ }^{1} \mathrm{H}$ NMR $(400 \mathrm{MHz}$, DMSO- $\left.d_{6}\right) \delta 8.99(\mathrm{~s}, 1 \mathrm{H}), 8.57(\mathrm{~d}, J=7.2 \mathrm{~Hz}, 1 \mathrm{H}), 8.18(\mathrm{~d}, J=$ $8.0 \mathrm{~Hz}, 1 \mathrm{H}), 8.07$ (d, $J=7.6 \mathrm{~Hz}, 1 \mathrm{H}), 8.00(\mathrm{~s}, 2 \mathrm{H}), 7.89(\mathrm{~s}, 1 \mathrm{H})$, $7.73(\mathrm{~s}, 1 \mathrm{H}), 7.70(\mathrm{~s}, 1 \mathrm{H}), 7.57(\mathrm{~s}, 1 \mathrm{H}), 7.32(\mathrm{~d}, J=5.6 \mathrm{~Hz}, 1 \mathrm{H})$, $7.26(\mathrm{~d}, J=7.2 \mathrm{~Hz}, 1 \mathrm{H}), 6.74(\mathrm{~s}, 1 \mathrm{H}), 5.91(\mathrm{~m}, 1 \mathrm{H}), 5.82(\mathrm{~m}, 1 \mathrm{H})$, $5.34(\mathrm{~m}, 1 \mathrm{H}), 5.23(\mathrm{~s}, 1 \mathrm{H}), 4.04(\mathrm{~s}, 3 \mathrm{H}), 3.96(\mathrm{~s}, 3 \mathrm{H}), 3.89(\mathrm{~s}, 3 \mathrm{H})$, $2.93(\mathrm{~s}, 3 \mathrm{H}) .{ }^{13} \mathrm{C}$ NMR $\left(125 \mathrm{MHz}, \mathrm{DMSO}-d_{6}\right) \delta 161.1,153.0,151.2$, $150.0,148.5$, 146.2, 136.5, 134.5, 134.0, 129.8, 129.2, 128.7, $128.4,127.3,126.1,125.0,124.4,122.9,122.3$, 119.1, 115.7, 114.3, 112.8, 110.6, 91.0, 76.5, 67.0, 62.3, 57.5, 56.4, 55.8. HRMS (EI) calcd for $\mathrm{C}_{31} \mathrm{H}_{28} \mathrm{O}_{6} \mathrm{~N}_{2} 524.1942[\mathrm{M}]^{+}$, found 524.1951.

3,9,10-Trimethoxy-5-(4-methoxy-3-((4-methylbenzyl)oxy)

phenyl)-2,3-dihydrooxazolo[2,3-a]isoquinolin-4-ium

(23k).

Compound 23k was prepared from compound $22 \mathbf{k}$ (52 $\mathrm{mg}, 0.1$ $\mathrm{mmol}$ ) as a yellow solid (45 mg, 92\%). ${ }^{1} \mathrm{H} \mathrm{NMR} \mathrm{(400} \mathrm{MHz,}$ DMSO- $\left.d_{6}\right) \delta 8.16(\mathrm{~s}, 1 \mathrm{H}), 7.99(\mathrm{~s}, 1 \mathrm{H}), 7.85(\mathrm{~s}, 1 \mathrm{H}), 7.39(\mathrm{~s}, 1 \mathrm{H})$, $7.33(\mathrm{~s}, 2 \mathrm{H}), 7.26(\mathrm{~s}, 1 \mathrm{H}), 7.20(\mathrm{~s}, 3 \mathrm{H}), 6.54(\mathrm{~s}, 1 \mathrm{H}), 5.31(\mathrm{~s}, 1 \mathrm{H})$, $5.13(\mathrm{~s}, 3 \mathrm{H}), 4.02(\mathrm{~s}, 3 \mathrm{H}), 3.95(\mathrm{~s}, 3 \mathrm{H}), 3.85(\mathrm{~s}, 3 \mathrm{H}), 2.82(\mathrm{~s}, 3 \mathrm{H})$, $2.28(\mathrm{~s}, 3 \mathrm{H}) .{ }^{13} \mathrm{C}$ NMR $\left(125 \mathrm{MHz}, \mathrm{DMSO}-d_{6}\right) \delta 160.6,152.4,150.8$, $147.6,145.7,137.3,136.0,133.9$, 133.5, 129.0, 127.9, 125.7, $124.5,123.7,122.4,118.5,114.1,112.3,110.0$, 90.5, 76.0, 70.0, 61.9, 57.1, 55.9, 55.4, 20.8. HRMS (EI) calcd for $\mathrm{C}_{29} \mathrm{H}_{29} \mathrm{O}_{6} \mathrm{~N}$ 487.1989 $[\mathrm{M}]^{+}$, found 487.1989.

5-(3-([1,1'-Biphenyl]-4-ylmethoxy)-4-methoxyphenyl)-3,9,10-trimethoxy-2,3-dihydrooxazolo[2,3-a]isoquinolin-4-ium

(23l).

Compound 231 was prepared from compound 221 (58 mg, 0.1 $\mathrm{mmol}$ ) as a yellow solid (45 mg, 81\%). ${ }^{1} \mathrm{H}$ NMR $(500 \mathrm{MHz}$, DMSO- $\left.d_{6}\right) \delta 8.20(\mathrm{~d}, J=6.8 \mathrm{~Hz}, 1 \mathrm{H}), 8.03(\mathrm{~d}, J=6.8 \mathrm{~Hz}, 1 \mathrm{H}), 7.90$ $(\mathrm{s}, 1 \mathrm{H}), 7.74(\mathrm{~d}, J=6.0 \mathrm{~Hz}, 2 \mathrm{H}), 7.70(\mathrm{~d}, J=6.0 \mathrm{~Hz}, 2 \mathrm{H}), 7.58(\mathrm{~d}, J$ $=6.0 \mathrm{~Hz}, 2 \mathrm{H}), 7.53-7.47(\mathrm{~m}, 3 \mathrm{H}), 7.40(\mathrm{t}, J=6.0 \mathrm{~Hz}, 1 \mathrm{H}), 7.33(\mathrm{~d}$, $J=6.4 \mathrm{~Hz}, 1 \mathrm{H}), 7.27(\mathrm{~d}, J=6.4 \mathrm{~Hz}, 1 \mathrm{H}), 6.63(\mathrm{~s}, 1 \mathrm{H}), 5.34(\mathrm{~m}$, 1H), $5.27(\mathrm{~m}, 3 \mathrm{H}), 4.07$ (s, 3H), $4.00(\mathrm{~s}, 3 \mathrm{H}), 3.93(\mathrm{~s}, 3 \mathrm{H}), 2.88(\mathrm{~s}$, $3 \mathrm{H}) .{ }^{13} \mathrm{C}$ NMR $\left(125 \mathrm{MHz}\right.$, DMSO- $\left.d_{6}\right) \delta 160.6,152.5,150.8,147.7$,
$145.7,139.9,139.7,136.0,135.8,133.9,129.0,128.4,127.6$, $126.8,126.6,125.7,124.4,123.8,122.4,118.6$, 114.1, 112.3, 110.0, 90.5, 76.0, 69.8, 61.8, 57.0, 55.8, 55.4. HRMS (EI) calcd for $\mathrm{C}_{34} \mathrm{H}_{31} \mathrm{O}_{6} \mathrm{~N} 549.2146[\mathrm{M}]^{+}$, found 549.2146.

5-(3-((4-(tert-Butyl)benzyl)oxy)-4-methoxyphenyl)-3,9,10-trimethoxy-2,3-dihydrooxazolo[2,3-a]isoquinolin-4-ium

(23m).

Compound 23m was prepared from compound 22m (56 mg, 0.1 $\mathrm{mmol}$ ) as a yellow solid (46 mg, 86\%). ${ }^{1} \mathrm{H}$ NMR $(500 \mathrm{MHz}$, DMSO- $\left.d_{6}\right) \delta 8.18(\mathrm{~d}, J=7.2 \mathrm{~Hz}, 1 \mathrm{H}), 8.02(\mathrm{~d}, J=6.8 \mathrm{~Hz}, 1 \mathrm{H}), 7.88$ $(\mathrm{s}, 1 \mathrm{H}), 7.44(\mathrm{~d}, J=5.6 \mathrm{~Hz}, 3 \mathrm{H}), 7.40(\mathrm{~d}, J=6.4 \mathrm{~Hz}, 2 \mathrm{H}), 7.30(\mathrm{~d}, J$ $=6.8 \mathrm{~Hz}, 1 \mathrm{H}), 7.23(\mathrm{~d}, J=6.8 \mathrm{~Hz}, 1 \mathrm{H}), 6.56(\mathrm{~s}, 1 \mathrm{H}), 5.32(\mathrm{~m}, 1 \mathrm{H})$, $5.26(\mathrm{~m}, 1 \mathrm{H}), 5.17(\mathrm{~m}, 2 \mathrm{H}), 4.05(\mathrm{~s}, 3 \mathrm{H}), 3.99(\mathrm{~s}, 3 \mathrm{H}), 3.88(\mathrm{~s}, 3 \mathrm{H})$, $2.82(\mathrm{~s}, 3 \mathrm{H}), 1.29(\mathrm{~s}, 9 \mathrm{H}) .{ }^{13} \mathrm{C}$ NMR $\left(125 \mathrm{MHz}, \mathrm{DMSO}-d_{6}\right) \delta 161.1$, $153.0,151.3,151.1,148.2,146.2$, 136.5, 134.5, 134.1, 128.3, 126.2, 125.7, 124.9, 124.3, 122.8, 119.0, 114.4, 112.7, 110.5, 91.0, 76.5, 70.3, 62.3, 57.5, 56.3, 55.9, 34.8, 31.6. HRMS (EI) calcd for $\mathrm{C}_{32} \mathrm{H}_{35} \mathrm{O}_{6} \mathrm{~N} 529.2459[\mathrm{M}]^{+}$, found 529.2459.

5-(3-((4-Isopropylbenzyl)oxy)-4-methoxyphenyl)-3,9,10-trimethoxy-2,3-dihydrooxazolo[2,3-a]isoquinolin-4-ium

(23n). Compound 23n was prepared from compound 22n (55 mg, 0.1 $\mathrm{mmol}$ ) as a yellow solid (50 mg, 90\%). ${ }^{1} \mathrm{H}$ NMR $(600 \mathrm{MHz}$, DMSO- $\left.d_{6}\right) \delta 8.18(\mathrm{~d}, J=6.0 \mathrm{~Hz}, 1 \mathrm{H}), 8.01(\mathrm{~d}, J=6.0 \mathrm{~Hz}, 1 \mathrm{H}), 7.87$ (s, 1H), 7.43 (d, $J=1.2 \mathrm{~Hz}, 1 \mathrm{H}), 7.39$ (d, $J=5.2 \mathrm{~Hz}, 2 \mathrm{H}), 7.31-$ $7.27(\mathrm{~m}, 3 \mathrm{H}), 7.22(\mathrm{~d}, J=5.6 \mathrm{~Hz}, 1 \mathrm{H}), 6.55(\mathrm{~d}, J=4.0 \mathrm{~Hz}, 1 \mathrm{H})$, $5.31(\mathrm{~m}, 1 \mathrm{H}), 5.24(\mathrm{~m}, 1 \mathrm{H}), 5.18(\mathrm{~m}, 1 \mathrm{H}), 5.13(\mathrm{~m}, 1 \mathrm{H}), 4.05(\mathrm{~s}$, $3 \mathrm{H}), 3.98(\mathrm{~s}, 3 \mathrm{H}), 3.87(\mathrm{~s}, 3 \mathrm{H}), 2.94-2.85(\mathrm{~m}, 1 \mathrm{H}), 2.82(\mathrm{~s}, 3 \mathrm{H})$, $1.20(\mathrm{~s}, 3 \mathrm{H}), 1.19(\mathrm{~s}, 3 \mathrm{H}) .{ }^{13} \mathrm{C}$ NMR $\left(125 \mathrm{MHz}, \mathrm{DMSO}-d_{6}\right) \delta 161.1$, $153.0,151.3,148.8,148.2$, 146.2, 136.5, 134.5, 134.4, 128.5, 126.9, 126.1, 124.9, 124.3, 122.8, 119.0, 114.4, 112.7, 110.5, 91.0, $76.4,70.4,62.3,57.4,56.3,55.9,33.7,24.3$. HRMS (EI) calcd for $\mathrm{C}_{31} \mathrm{H}_{33} \mathrm{O}_{6} \mathrm{~N} 515.2302[\mathrm{M}]^{+}$, found 515.2295.

5-(3-((3,5-Dimethoxybenzyl)oxy)-4-methoxyphenyl)-3,9,10-trimethoxy-2,3-dihydrooxazolo[2,3-a]isoquinolin-4-ium

(23o). Compound 23o was prepared from compound 220 (56 mg, 0.1 mmol) as a yellow solid (51 mg, 95\%). ${ }^{1} \mathrm{H}$ NMR $(500 \mathrm{MHz}$, DMSO- $\left.d_{6}\right) \delta 8.18(\mathrm{~d}, J=8.5 \mathrm{~Hz}, 1 \mathrm{H}), 8.00(\mathrm{~d}, J=9.0 \mathrm{~Hz}, 1 \mathrm{H}), 7.87$ $(\mathrm{m}, 1 \mathrm{H}), 7.39(\mathrm{~s}, 1 \mathrm{H}), 7.32-7.26(\mathrm{~m}, 1 \mathrm{H}), 7.24(\mathrm{~d}, J=8.5 \mathrm{~Hz}, 1 \mathrm{H})$, $6.62(\mathrm{~s}, 2 \mathrm{H}), 6.52(\mathrm{~s}, 1 \mathrm{H}), 6.47(\mathrm{~s}, 1 \mathrm{H}), 5.33(\mathrm{~m}, 1 \mathrm{H}), 5.26-5.17(\mathrm{~m}$, $1 \mathrm{H}), 5.15(\mathrm{~s}, 2 \mathrm{H}), 4.05(\mathrm{~s}, 3 \mathrm{H}), 3.98(\mathrm{~s}, 3 \mathrm{H}), 3.90(\mathrm{~s}, 3 \mathrm{H}), 3.74(\mathrm{~s}$, $6 \mathrm{H}), 2.84(\mathrm{~s}, 3 \mathrm{H}) .{ }^{13} \mathrm{C}$ NMR (125 MHz, DMSO- $\left.d_{6}\right) \delta 161.1,161.1$, $153.0,151.4,148.0,146.2,139.5$, 136.5, 134.4, 126.2, 124.9, 124.2, 123.0, 119.0, 114.7, 112.9, 110.5, 106.1, 99.8, 91.0, 76.4, 70.4, 62.3, 57.5, 56.4, 55.9, 55.7. HRMS (EI) calcd for $\mathrm{C}_{30} \mathrm{H}_{31} \mathrm{O}_{8} \mathrm{~N}$ 533.2044 $[\mathrm{M}]^{+}$, found 533.2031.

\section{Biology}

Materials. Fluorescein diacetate (FD) and loperamide (LPA) were purchased from TCI (Tokyo Japan), Luciferin Detection Reagent (LDR) was purchased from Promega Corporation (USA). $\quad N$-(2-Butyl-1,3-dioxo-2,3-dihydro-1 $H$-phenalen-6-yl)-2chloroacetamide (NCEN) and D-luciferin methyl ester (DME) were synthesized by authors according to the previously reported synthetic scheme. ${ }^{37,38}$ Nevadensin was purchased from Chengdu Preferred Biotech Co., Ltd. (Chengdu, China). Pooled human liver microsomes (HLMs, from 50 donors, lot no. X008067) were obtained from Bioreclamation IVT (Baltimore, 
MD, USA) and stored at $-80{ }^{\circ} \mathrm{C}$ until use. DMSO was purchased from fisher. Phosphate buffer was prepared using Millipore water and then stored at $4{ }^{\circ} \mathrm{C}$ until use. All tested compounds were solved by DMSO and stored at $4{ }^{\circ} \mathrm{C}$ until use. LC grade acetonitrile and DMSO (Tedia, USA) were used throughout.

hCE1 inhibition assay. DME was used as a probe substrate for evaluating the inhibitory effects of all DCZ0358 derivatives on hCE1, while nevadensin (a specific hCE1 inhibitor) was used as a positive control. ${ }^{39}$ Briefly, $100 \mu \mathrm{L}$ incubation mixture containing $91 \mu \mathrm{L}$ PBS ( $\mathrm{pH}$ 6.8), $2 \mu \mathrm{L}$ inhibitor at different concentrations and $5 \mu \mathrm{L}$ HLM $\left(1 \mu \mathrm{g} \mathrm{mL}{ }^{-1}\right.$, final concentration), were pre-incubated at $37{ }^{\circ} \mathrm{C}$ for $10 \mathrm{~min}$. Subsequently, $2 \mu \mathrm{L}$ DME (3 $\mu \mathrm{M}$ final concentration, close to the $K_{\mathrm{m}}$ value of DME in HLM) was added to initiate the reaction. After incubating for $10 \mathrm{~min}$ at $37^{\circ} \mathrm{C}$ in a shaking bath, the reaction was stopped by the addition of LDR $(100 \mu \mathrm{L})$. The microplate reader (SpectraMax® ${ }^{\circledR}$ iD3, Molecular Devices, Austria) was used for luminescence measurements. The gain value of luminescence detection was set at 140 volts, and the integration time was set at $1 \mathrm{~s}$. The chemical structure of DME and its hydrolytic metabolite (Dluciferin), as well as the detection conditions for D-luciferin are depicted in Table S1. $\dagger$ The negative control incubation (DMSO only) was carried out under the same conditions. The residual activity was calculated using the following formula, the residual activity $(\%)=$ (the florescence intensity in the presence of inhibitor)/the florescence intensity in negative control $\times 100 \%$. The residual activities are show in Fig. S1. $\dagger$

hCE2 inhibition assay. The inhibitory effects of all DCZ0358 derivatives on hCE2 were investigated using fluorescein diacetate (FD) as a specific probe substrate, ${ }^{\mathbf{4 0}}$ while LPA was used as a positive inhibitor of hCE2 in this study. ${ }^{41}$ In brief, $200 \mu \mathrm{L}$ incubation mixture containing 0.1 M PBS (PH = 7.4), human liver microsomes $\left(2 \mu \mathrm{g} \mathrm{mL} \mathrm{m}^{-1}\right.$, final concentration) and each inhibitor. After $10 \mathrm{~min}$ pre-incubation at $37^{\circ} \mathrm{C}$, the reaction was initiated by adding FD $(5 \mu \mathrm{M}$, final concentration, close to the $K_{\mathrm{m}}$ value of FD in HLM). After incubating for $30 \mathrm{~min}$ at $37^{\circ} \mathrm{C}$ in a shaking bath, the reaction was stopped by the addition of acetonitrile $(200 \mu \mathrm{L})$. The chemical structure of FD and its hydrolytic metabolite (fluorescein), as well as the detection conditions for fluorescein are depicted in Table S1. $\dagger$ The negative control incubation (DMSO only) was also carried out under the same conditions. ${ }^{42}$ The residual activity was calculated using the formula mentioned above in hCE1 inhibition assay. The residual activities are shown in Fig. S1. $\dagger$

Cell culture and fluorescence imaging analyses. In view of that hCE2 was an intracellular enzyme, the inhibition potential of 230 was investigated in living HepG2 cells. The HepG2 cells were cultured in Modified Eagle's Medium (MEM) with $5 \% \mathrm{CO}_{2}$ and $0.1 \%$ antibiotic-antimycoticmix antibiotic at $37{ }^{\circ} \mathrm{C}$, supplemented with $10 \%$ fetal bovine serum (FBS) and used NCEN as substrate probe to assay the $\mathbf{2 3 0}$ inhibition potential toward hCE2. NCEN, ${ }^{43}$ another specific optical probe substrate for hCE2, the structure and hydrolytic site were shown in Fig. S2(A). $\dagger$

For fluorescence imaging, HepG2 cells were seeded in 96well plates ( 8000 cells per well) with complete medium and then incubated for 24 hours. Afterwards, the cells were washed twice with FBS-free culture medium and then preincubated in the medium containing 23o (prepared in FBS-free at various concentrations) for $30 \mathrm{~min}$ with $5 \% \mathrm{CO}_{2}$ at $37{ }^{\circ} \mathrm{C}$. HepG2 cells were then co-incubated with NCEN (final concentration, $10 \mu \mathrm{M}$ ) for another $50 \mathrm{~min}$ to assess the intracellular hCE2 function, respectively. The living cells were imaged and analyzed using an ImageXpress ${ }^{\circledR}$ Micro Confocal High-Content Imaging system (Molecular Devices, Austria).

\section{Conflicts of interest}

There are no conflicts to declare.

\section{Acknowledgements}

We are grateful to Xiaolong $\mathrm{Li}$ and Hui Li for their early exploration of synthesizing this type of quaternary ammonium. This research was supported by grants from the National Key R \& D Program of China (2016YFA0502301, 2017YFC1700200, 2017YFC1702000), National Major Scientific and Technological Special Project for "Significant New Drugs Development" (2018ZX09711002), National Natural Science Foundation of China (81573350, 81273546, 81973286, 8192207), Natural Science Foundation of Shanghai, China (19ZR1467800), and Program of Shanghai Academic/Technology Research Leader (18XD1403600).

\section{Notes and references}

1 L. W. Zou, Q. Jin, D. D. Wang, Q. K. Qian, D. C. Hao, G. B. Ge and L. Yang, Curr. Med. Chem., 2018, 25, 1627-1649.

2 D. D. Wang, L. W. Zou, Q. Jin, J. Hou, G. B. Ge and L. Yang, Fitoterapia, 2017, 117, 84-95.

3 D. D. Wang, L. W. Zou, Q. Jin, J. Hou, G. B. Ge and L. Yang, Acta Pharm. Sin. B, 2018, 8, 699-712.

4 P. M. Potter, J. S. Wolverton, C. L. Morton, M. Wierdl and M. K. Danks, Cancer Res., 1998, 58, 3627-3632.

5 S. P. Sanghani, S. K. Quinney, T. B. Fredenburg, W. I. Davis, D. J. Murry and W. F. Bosron, Drug Metab. Dispos., 2004, 32, 505-511.

6 E. T. Williams, K. O. Jones, G. D. Ponsler, S. M. Lowery, E. J. Perkins, S. A. Wrighton, K. J. Ruterbories, M. Kazui and N. A. Farid, Drug Metab. Dispos., 2008, 36, 1227-1232.

7 A. Watanabe, T. Fukami, M. Nakajima, M. Takamiya, Y. Aoki and T. Yokoi, Drug Metab. Dispos., 2009, 37, 1513-1520.

8 S. Chen, M. F. Yueh, C. Bigo, O. Barbier, K. Wang, M. Karin, N. Nguyen and R. H. Tukey, Proc. Natl. Acad. Sci. U. S. A., 2013, 110, 19143-19148.

9 R. H. Mathijssen, R. J. van Alphen, J. Verweij, W. J. Loos, K. Nooter, G. Stoter and A. Sparreboom, Clin. Cancer Res., 2001, 7, 2182-2194.

10 G. Dranitsaris, A. Shah, B. Spirovski and M. Vincent, Clin. Colorectal Cancer, 2007, 6, 367-373.

11 S. K. Quinney, S. P. Sanghani, W. I. Davis, T. D. Hurley, Z. Sun, D. J. Murry and W. F. Bosron, J. Pharmacol. Exp. Ther., 2005, 313, 1011-1016. 
12 A. Alimonti, A. Gelibter, I. Pavese, F. Satta, F. Cognetti, G. Ferretti, D. Rasio, A. Vecchione and M. Di Palma, Cancer Treat. Rev., 2004, 30, 555-562.

13 Z. P. Mai, K. Zhou, G. B. Ge, C. Wang, X. K. Huo, P. P. Dong, S. Deng, B. J. Zhang, H. L. Zhang, S. S. Huang and X. C. Ma, J. Nat. Prod., 2015, 78, 2372-2380.

14 Z.-J. Zhang, X.-K. Huo, X.-G. Tian, L. Feng, J. Ning, X.-Y. Zhao, C.-P. Sun, C. Wang, S. Deng, B.-J. Zhang, H.-L. Zhang and Y. Liu, RSC Adv., 2017, 7, 28702-28710.

15 L. W. Zou, Y. G. Li, P. Wang, K. Zhou, J. Hou, Q. Jin, D. C. Hao, G. B. Ge and L. Yang, Eur. J. Med. Chem., 2016, 112, 280-288.

16 L. D. Hicks, J. L. Hyatt, S. Stoddard, L. Tsurkan, C. C. Edwards, R. M. Wadkins and P. M. Potter, J. Med. Chem., 2009, 52, 3742-3752.

17 M. J. Hatfield, L. G. Tsurkan, J. L. Hyatt, C. C. Edwards, A. Lemoff, C. Jeffries, B. Yan and P. M. Potter, J. Nat. Prod., 2013, 76, 36-44.

18 B. Li, G. Wang, Z. Xu, Y. Zhang, X. Huang, B. Zeng, K. Chen, J. Shi, H. Wang and W. Zhu, Eur. J. Med. Chem., 2014, 77, 204-210.

19 B. Li, S. Xue, Y. Yang, J. Feng, P. Liu, Y. Zhang, J. Zhu, Z. Xu, A. Hall, B. Zhao, J. Shi and W. Zhu, Sci. Rep., 2017, 7, 41287.

20 L. Gao, B. Li, G. Yang, P. Liu, X. Lan, S. Chang, Y. Tao, Z. Xu, B. Xie, X. Sun, Y. Wang, L. Hu, D. Yu, Y. Xie, W. Bu, X. Wu, W. Zhu and J. Shi, Cancer Lett., 2018, 421, 135-144.

21 B. Li, G. Wang, M. Yang, Z. Xu, B. Zeng, H. Wang, J. Shen, K. Chen and W. Zhu, Eur. J. Med. Chem., 2013, 70, 677-684.

22 F. Baur, D. Beattie, D. Beer, D. Bentley, M. Bradley, I. Bruce, S. J. Charlton, B. Cuenoud, R. Ernst, R. A. Fairhurst, B. Faller, D. Farr, T. Keller, J. R. Fozard, J. Fullerton, S. Garman, J. Hatto, C. Hayden, H. He, C. Howes, D. Janus, Z. Jiang, C. Lewis, F. Loeuillet-Ritzler, H. Moser, J. Reilly, A. Steward, D. Sykes, L. Tedaldi, A. Trifilieff, M. Tweed, S. Watson, E. Wissler and D. Wyss, J. Med. Chem., 2010, 53, 3675-3684.

23 S. R. Haadsma-Svensson, K. A. Cleek, D. M. Dinh, J. N. Duncan, C. L. Haber, R. M. Huff, M. E. Lajiness, N. F. Nichols, M. W. Smith, K. A. Svensson, M. J. Zaya, A. Carlsson and C. H. Lin, J. Med. Chem., 2001, 44, 47164732 .

24 H. Franzyk, S. R. Jensen, C. E. Olsen and J. H. Rasmussen, Nucleosides, Nucleotides Nucleic Acids, 2002, 21, 23-43.

25 E. L. Eliel, T. N. Ferdinand and S. M. Carolyn, J. Org. Chem., 1954, 19, 1693-1698.
26 D. S. Kashdan, J. A. Schwartz and H. Rapoport, J. Org. Chem., 1982, 47, 2638-2643.

27 J. M. Hook, L. N. Mander and R. Urech, J. Org. Chem., 1984, 49, 3250-3260.

28 M. Kondo, Y. Inoue, Y. Koeduka, M. Funahashi, A. Heya, N. Matsuo and N. Kawatsuki, Chem. Lett., 2015, 44, 10101012.

29 M. Cushman, A. Abbaspour and Y. P. Gupta, J. Am. Chem. Soc., 1990, 112, 5898.

30 K. Q. Ling, J. H. Ye, X. Y. Chen, D. J. Ma and J. H. Xu, Tetrahedron, 1999, 55, 9185-9204.

31 S. Sundriyal, P. B. Chen, A. S. Lubin, G. A. Lueg, F. Li, A. J. P. White, N. A. Malmquist, M. Vedadi, A. Scherf and M. J. Fuchter, MedChemComm, 2017, 8, 1069-1092.

32 M. Spulak, J. Pourova, M. Voprsalova, J. Mikusek, J. Kunes, J. Vacek, M. Ghavre, N. Gathergood and M. Pour, Eur. J. Med. Chem., 2014, 74, 65-72.

33 D. D. Wang, Q. Jin, L. W. Zou, J. Hou, X. Lv, W. Lei, H. L. Cheng, G. B. Ge and L. Yang, Chem. Commun., 2016, 52, 3183-3186.

34 J. Wang, E. T. Williams, J. Bourgea, Y. N. Wong and C. J. Patten, Drug Metab. Dispos., 2011, 39, 1329-1333.

35 Y. Q. Wang, Z. M. Weng, T. Y. Dou, J. Hou, D. D. Wang, L. L. Ding, L. W. Zou, Y. Yu, J. Chen, H. Tang and G. B. Ge, Int. J. Biol. Macromol., 2018, 120, 1944-1954.

36 D. Abigerges, J. P. Armand, G. G. Chabot, L. Da Costa, E. Fadel, C. Cote, P. Herait and D. Gandia, J. Natl. Cancer Inst., 1994, 86, 446-449.

37 D. D. Wang, Q. Jin, L. W. Zou, J. Hou, X. Lv, W. Lei, H. L. Cheng, G. B. Ge and L. Yang, Chem. Commun., 2016, 52, 3183-3186.

38 L. Feng, Z. M. Liu, J. Hou, X. Lv, J. Ning, G. B. Ge, J. N. Cui and L. Yang, Biosens. Bioelectron., 2015, 65, 9-15.

39 Y. Q. Wang, Z. M. Weng, T. Y. Dou, J. Hou, D. D. Wang, L. L. Ding, L. W. Zou, Y. Yu, J. Chen, H. Tang and G. B. Ge, Int. J. Biol. Macromol., 2018, 120, 1944-1954.

40 K. C. Leibman, Drug Metab. Dispos., 1973, 1, 487-488.

41 D. Abigerges, J. P. Armand, G. G. Chabot, L. Dacosta, E. Fadel, C. Cote, P. Herait and D. Gandia, J. Natl. Cancer Inst., 1994, 86, 446-449.

42 Z. M. Weng, G. B. Ge, T. Y. Dou, P. Wang, P. K. Liu, X. H. Tian, N. Qiao, Y. Yu, L. W. Zou, Q. Zhou, W. D. Zhang and J. Hou, Bioorg. Chem., 2018, 77, 320-329.

43 X. W. Cheng, X. Lv, H. Y. Qu, D. D. Li, M. M. Hu, W. Z. Guo, G. B. Ge and R. H. Dong, Acta Pharm. Sin. B, 2017, 7, 657-664. 